\title{
Calcium loss on root canal dentin after Ethylenediaminetetraacetic acid (EDTA) application with different varians
}

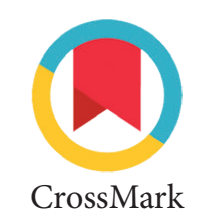

\author{
Juni J. Nugroho, Christine A. Rovani, Hermiati Daharuddin*, \\ Aries C. Trilaksana, Nurhayaty Natsir, Andi Sumidarti
}

Department of Conservative Dentistry, Faculty of Dentistry, Hasanuddin University, Makassar, Indonesia
* Correspondence to: Hermiati Daharuddin, Department of Conservative Dentistry, Faculty of Dentistry, Hasanuddin University, Makassar, Indonesia

hermiatidaharuddin@gmail.com

Received: 5 August 2018 Revised: 26 February 2019

Accepted: 28 February 2019

Available Online 1 August 2019

\section{Abstract}

Objective: This study aimed to compare calcium loss on root canal dentin before and after EDTA application with different varians and concentration with or without surfactant.

Material and Methods: Samples are mandibular premolar teeth single root canal, which is divided into 4 groups: Ethylenediaminetetraacetic Acid (EDTA) gel, cream, solution and negative control. They are decoronated in Cemento-Enamel Junction (CEJ), then prepared with Crown Down Pressureless (CDP) technique and separated bucolingual direction. One side was applied in EDTA according their respective groups and the other side was set as sample before application. Samples before and after application of each group are destructed then subsequently measured for their $\mathrm{Ca}^{2+1}$ s amount using Atomic Absorption Spectrophotometry (AAS). Data were collected and analyzed using ANOVA and Tukey Post Hoc test.

Results: This showed significant differences between $\mathrm{Ca}^{2+}$ amount in root canal dentin before and after application either on EDTA gel, cream, or solution as well as on negative control group $(p<0.05)$.

Conclusion: Application of EDTA solution causes the highest calcium loss compared to EDTA gel and cream.
Keywords: Calcium loss, EDTA, Root canal dentin

Cite This Article: Nugroho JJ, Rovani CA, Daharuddin H, Trilaksana AC, Natsir N, Sumidarti A. 2019. Calcium loss on root canal dentin after Ethylenediaminetetraacetic acid (EDTA) application with different varians. Journal of Dentomaxillofacial Science 4(2): 79-82. D0I: 10.15562/ jimfs.v4i2.781

\section{Introduction}

Success of root canal treatment depends on microorganism elimination in root canal and prevention of recurrent infections. ${ }^{1-3}$ During the root canal instrumentation, chemicals are used as irrigant and lubricant to facilitate the movement of instrument inside root canal, so it reduce mechanical stress of root canal instrument and prevent fracture instrument in root canal. ${ }^{4,5}$

Ethylenediaminetetraacetic acid (EDTA) is the most widely used lubricant in root canal treatment. ${ }^{6}$ EDTA help remove smear layer from root canal system mainly dominated by inorganic components. ${ }^{3,4}$ EDTA's capability in removing inorganic components influences chemical structure of root canal dentin. EDTA may cause a change in ratio of $\mathrm{Ca}^{2+}: \mathrm{PO}_{4}^{3-}$ in root canal dentin, which will then lead to microhardness decrease of root canal dentin. It may also affect strength of root canal sealer.

\section{Material and Methods}

Samples that met the inclusion criteria was taken and decoronated on CEJ. Root canal preparation used ProTaper hand use (S1, Sx, S2, F1, F2-F5) and was irrigated with $\mathrm{NaOCl} 2.5 \%$ every turn of file. Samples was divided into 4 groups with 6 teeth for each. First group applied EDTA gel, second group
EDTA cream, third group EDTA liquid, and fourth group applied no-EDTA (negative control).

After samples was prepared, then it was separated longitudinally in buccolingual direction figure 1 . One side of sample would be applied with EDTA according to each group and the other side was set as sample prior to application. Except in negative control group, both sides were not applied with EDTA.

Samples was put into $110^{\circ} \mathrm{C}$ oven for 1 hour and then stored in desiccator for 15 minutes. They were inserted into $450^{\circ} \mathrm{C}$ furnace machine afterwards for 8 hours until it ashed. Then it was proceeded by wet destruction. It was dissolved with heated 10 $\mathrm{ml}$ of $\mathrm{HCl} 10 \mathrm{M}$ solution and then with $\mathrm{HNO}_{3} 0.1 \mathrm{M}$ solution to each sample until solution mixture reached $100 \mathrm{ml}$ figure 2. Sample that had turned into solution was filtered to further measure calcium amount by using AAS machine figure 3 .

\section{Results}

Based on Wilcoxon Signed Ranks test table 1, all groups show value of $\mathrm{p}=0.028(\mathrm{p}<0.05)$. It means that there are significant differences between $\mathrm{Ca}^{2+}$ amount in root canal dentin before and after EDTA application either on EDTA gel, cream, or solution as well as on negative control group.

Based on ANOVA test, it results value of $\mathrm{p}=0.000$ 


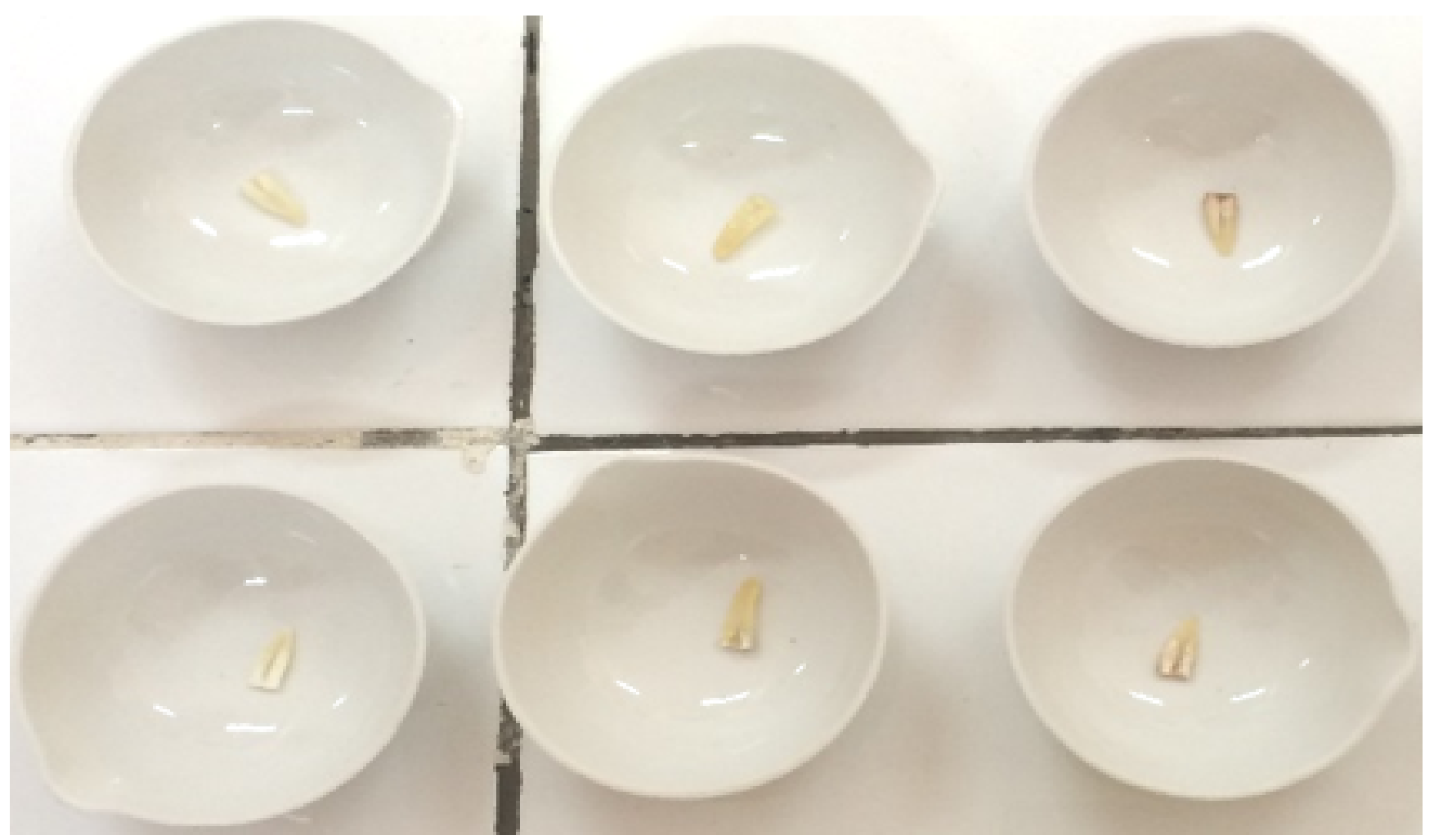

Figure 1 Samples are ready to be applied EDTA

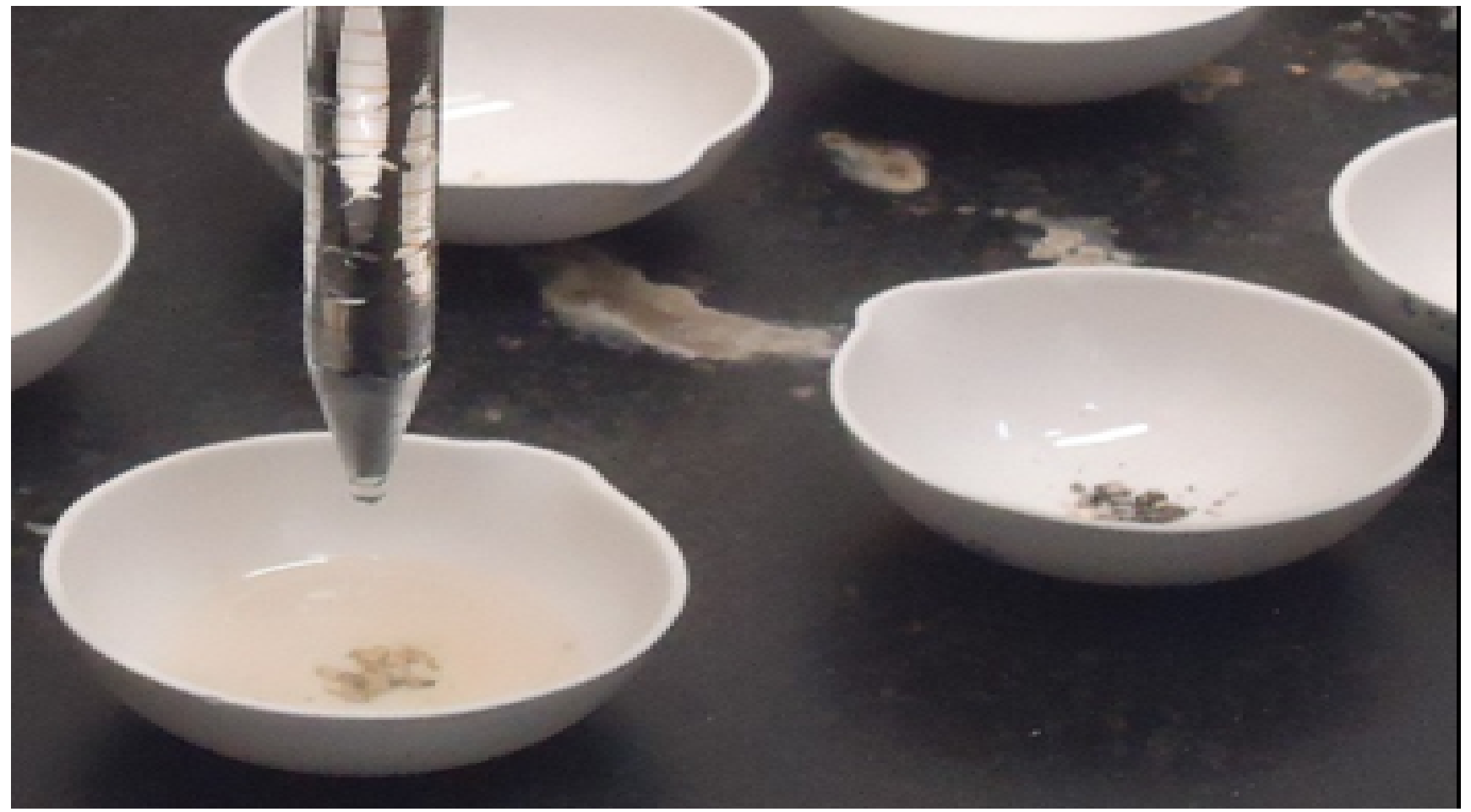

Figure 2 Samples are dissolved with heated $10 \mathrm{ml}$ of $\mathrm{HCl} 10 \mathrm{M}$, then mixed with $\mathrm{HNO}_{3} 0.1 \mathrm{M}$ until it reached $100 \mathrm{ml}$ 
Table 1 Difference in $\mathrm{Ca}^{2+}$ amount in root canal dentin before and after EDTA application based on respective EDTA variants

\begin{tabular}{llccc}
\hline \multirow{2}{*}{ EDTA } & $\mathrm{N}$ & \multicolumn{2}{c}{ Total Ca2 $+(\mathrm{mg} / \mathrm{g})$} & \multirow{2}{*}{ MEDIAN } \\
& & \multicolumn{3}{c}{ Pre test } \\
\cline { 3 - 4 } & & 216.736 & 209.474 & $.028^{*}$ \\
& 6 & $(208.695-231.280)$ & $(200.762-224.907)$ & \\
& & 6 & 240.333 & \\
& Cream & $.028^{*}$ & $(190.064-286.899)$ & \\
& 225.986 & $(207.017-299.686)$ & 218.445 & $.028^{*}$ \\
Solvent & 6 & 250.672 & $(180.711-257.106)$ & \\
& & $(210.104-288.920)$ & 228.085 & $.028^{*}$ \\
Control & 6 & 228.847 & & \\
\hline
\end{tabular}

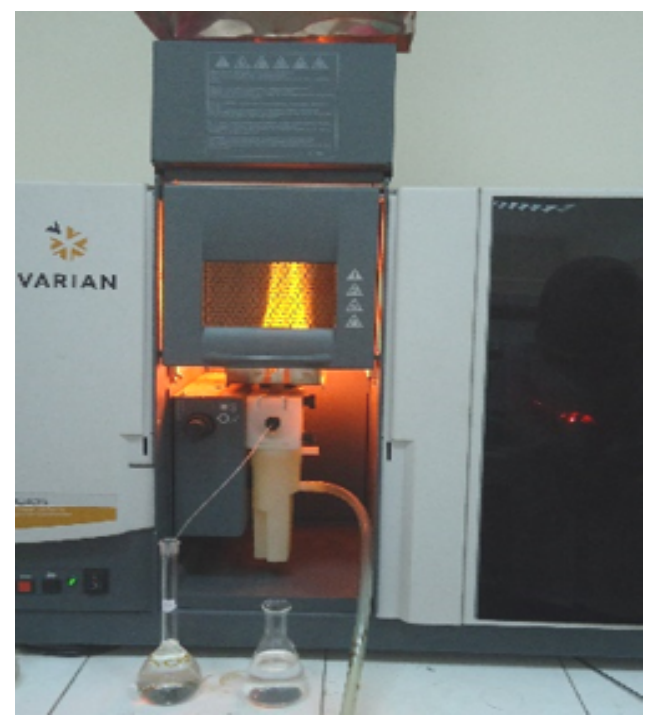

Figure 3 AAS machine is reading the sample

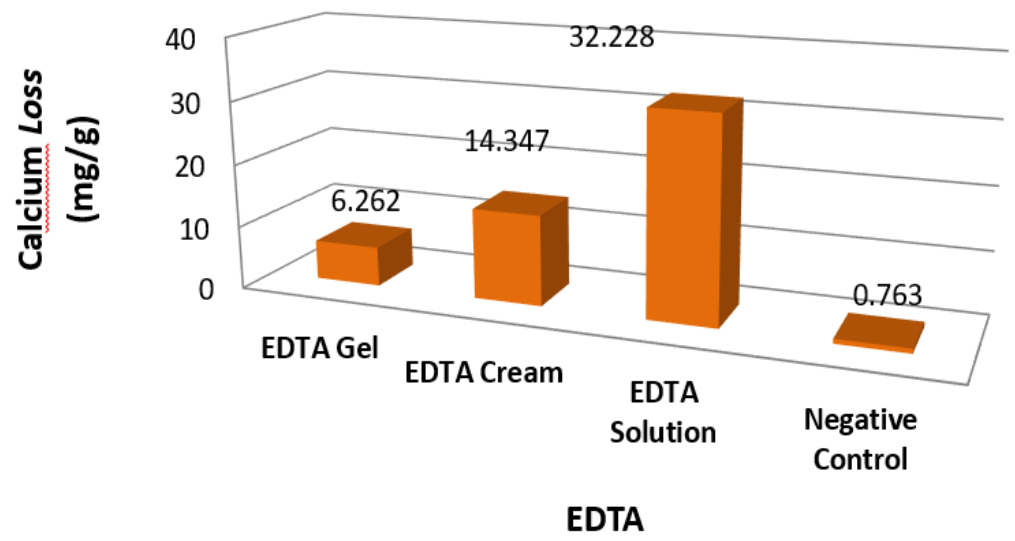

Figure 4 Calcium loss differences in each variant of EDTA. (private collection) $(\mathrm{p}<0.05)$, where the highest calcium loss seen in group EDTA solution with mean value of 32.228 $\mathrm{mg} / \mathrm{g}$ (figure 4). EDTA solution which was used in this study contained EDTA $17 \%$ added with surfactant benzalkonium bromide. Whereas both EDTA gel and cream contained EDTA 15\% added with surfactant urea peroxide.

\section{Discussion}

In root canal dentin, EDTA reacts with $\mathrm{Ca}^{2+}$ in apatite crystals and causes dentin microstructure change through change in ratio of $\mathrm{Ca}^{2+}: \mathrm{PO}_{4}{ }^{3-8}$ EDTA's capability in causing decrease $\mathrm{Ca}^{2+}$ amount in root canal dentin was consistent EDTA $15 \%$ was able to reduce more $\mathrm{Ca}^{2+}$ amount than $10 \%$ citric acid. $^{6}$

EDTA's capability to dissolve $\mathrm{Ca}^{2+}$ in root canal dentin showed in the number of smear layer removed at the time of instrumentation. This was in line with Kamakshi et al. concluded EDTA $17 \%$ was highly effective to remove smear layer. ${ }^{7}$ In accordance with the study, Qian et al. ${ }^{8}$ in root canal dentin smear layer concludes EDTA and citric acid had the ability to remove smear layer by the erosion effect on peritubular and intertubular root canal dentin. ${ }^{8}$ The erosion would then affect microhardness decrease of root canal dentin due to decomposition of root canal dentin components. ${ }^{8,9}$ EDTA in cream or pasta variant had a low flow-rate. ${ }^{10,11}$ This assuredly, would make it difficult for material to flow in narrow apical portion and to penetrate far into root canal dentin. As a result, chelation action by EDTA cream would be limited. Nevertheless, addition of surfactant urea peroxide in EDTA cream would help enhance effectiveness compared to EDTA gel although flow rate is slightly higher yet contains no surfactant. ${ }^{11,12}$

Meanwhile, EDTA solution had the highest flow capacity so it could flow to apical end and penetrate deeper into dentin. ${ }^{10,12}$ This was in accordance with result of our study that calcium loss in EDTA solution was the highest.

EDTA $17 \%$ had ability to dissolve more $\mathrm{Ca}^{2+}$ than EDTA 15\%, which was added with cationic surfactant $0.1 \% \cdot{ }^{13}$ In line with those, Handa et al. ${ }^{14}$ stated EDTA $17 \%$ is more effective in dissolving dentin-even approaching $70 \%$ mass of dentin. ${ }^{14}$ A research on smear layer and dentin erosion capacity caused by EDTA with various concentrations $(15 \%, 10 \%, 5 \%$ and $1 \%)$. It is known that EDTA concentration affects the magnitude of value decrease $\mathrm{Ca}^{2+}$ amount in root canal dentin. On the other words, concentration of EDTA was 
directly proportional to value of calcium loss. ${ }^{15}$

\section{Conclusion}

Based on our study, it can be concluded $\mathrm{Ca}^{2+}$ amount in root canal dentin before application decreases compared after application of EDTA gel, cream and solution; and application of EDTA solution causes the highest loss of $\mathrm{Ca}^{2+}$ compared to EDTA gel and cream. In clinical application, it is suggested EDTA selection is not based on simplicity of application but on variant that gives the lowest impact of calcium loss

\section{Acknowledgment}

In this study, we appreciate very much to Sarwo Edy, drg. and Irma Ariany Syam, drg. for assisting researcher in analyzing the data. And also Laboratory of Chemistry Faculty of Science and Technology, Islam Negeri University, for providing facilities required to accomplished this research work.

\section{Conflict of Interest}

The authors report no conflict of interest.

\section{References}

1. Torabinejad M, Rivera EM. Cleaning and shaping. In: Torabinejad M, Walton RE. Principles and practice of endodontics. 4th ed. St. Louis: Saunders Elsevier. 2009. p. 206.

2. Cohen S, Hargreaves K. Pathways of the pulp. 9th ed. St. Louis: Mosby; 2006. p. 179.

3. Krasner P, Rankow HJ, Abrams ES. Access opening and canal location. In: Endodontics colleagues for excellence. Chicago: Am Assoc Endod. 2010.

4. Ford TR. Endodontics: problem solving in clinical practice. 2003. p. 97-102.

5. Tartari T, Souza P, Almeida B, et al. A new weak chelator in endodontics: effects of different irrigation regimens with etidronate on root dentin microhardness. Int $J$ of Dent 2013;743018: 1-5.
6. Cobankara FK, Erdogan H, Hamurcu M. Effects of chelating agents on the mineral content of root canal dentin. Oral Surg Oral Med Oral Pathol Oral Radiol Endod 2011;112: e149-154.

7. Kamakshi, Suvarna N, Shetty HK, et al. Relation between calcium loss and its effect on microhardness root canal dentin following treatment with $17 \%$ ethylenediaminetetraacetic ecid (EDTA) at different time interval: an exvivo study. J Int Med and Dent 2014;1: 75-78.

8. Qian W, Shen Y, Haapasalo M. Quantitative analysis of the effect of irrigant solution sequences on dentin erosion. J Endod 2011;37: 1437-1441.

9. Turk T, Kaval ME, Sen BH. Evaluation of the smear layer removal and erosive capacity of EDTA, boric acid, citrid acid and desy clean solution: an in vitro study. BMC Oral Health 2015;15: 1-5.

10. Machado-Silveiro LH, Gonzalez-Lopez S, GonzalezRodriguez MP. Decalcification of root canal dentin by citric acid, EDTA and sodium citrate. Int Endo J 2004;37: 365-369.

11. Napte BG, Srinidhi SR. Evaluation of the action of chelating agents of the microhardness of superficial layer of root canal lumen dentin. World J Dent 2014;5: 124-128.

12. Kalluru R, Kumar ND, Ahmed S, et al. Comparative evalution of the effect of EDTA, EDTAC, $\mathrm{NaOCl}$, and MTAD on microhardness of human dentin-an invitro study. J Clin \& Diag Res 2014;8: 39-41.

13. Bagmar S. Effect of different surfactant addition to edta on microhardness of root dentin: an in vitro study. Int J Res Dent 2013;3: 120-124.

14. Handa A, Handa RS. Influence of root canal irrigants on dental tissues: a review of literature. Indian J Dent Sci 2013;5: 73-75.

15. Ali SG, Mulay S. Effect of EDTA-urea peroxide combination at different time periods on smear layer and root dentin surface: a sem study. Int J Innov \& App Studies 2014;8: 232-235.

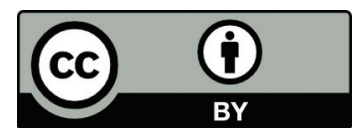

This work is licensed under a Creative Commons Attribution 